\title{
Biomarcadores da tuberculose: uma revisão da literatura
}

William Machado de Souza', Djuli Milene Hermes²

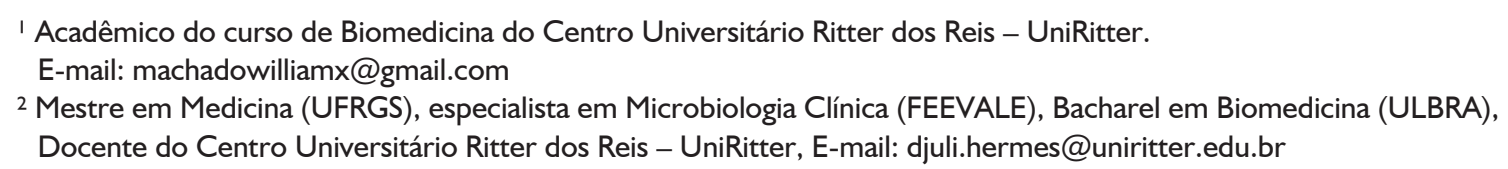

Recebido em: 24 dez. 2018. Aceito: 8 fev. 2018. DOI: http://dx.doi.org/I0.21674/2448-0479.5I.27-46

\section{Resumo}

A tuberculose é uma infecção micobacteriana comumente causada pelo agente etiológico Mycobacterium tuberculosis, podendo também ser desencadeada por outras bactérias do gênero Mycobacterium. Ainda que bem documentada, mais de um século após sua descoberta, situa-se como a doença infecciosa que mais mata no mundo. Configura-se também problema socioeconômico importante, atingindo em especial as camadas mais pobres da população e comprometendo seriamente sua capacidade produtiva. Os métodos diagnósticos tradicionais para a doença consistem da baciloscopia e cultura, recentemente adotando os testes moleculares rápidos, todos com limitações significativas, como a incapacidade de discriminar entre casos de tuberculose ativa e latente, sensibilidade inconsistente e incapacidade de oferecer prognósticos. A presente revisão da literatura procurou elucidar os atuais avanços na pesquisa de biomarcadores da infecção nos últimos 5 anos com o emprego da metodologia ELISA. Foram verificadas e comparadas evidências apresentadas pelos estudos e as performances diagnósticas alcançadas em cada contexto. Constatou-se uma evidente heterogeneidade nas respostas imunológicas entre populações e indivíduos, provável fruto da diversidade genética do patógeno que possui linhagens intercontinentais e regionais, bem como diferenças particulares nas expressões de alguns biomarcadores, seja por variáveis genéticas ou mesmo outras doenças de base; a homologia dos antígenos pesquisados com outras espécies de bactérias também foi uma problemática. Fica claro que questões genéticas particulares de populações e do próprio agente infeccioso precisam ser melhor consideradas nesses estudos, a fim de alcançar um perfil sorológico suficientemente sensível e específico para triagem clínica e diagnóstico destes pacientes.

Palavras-Chave: Biomarcadores. Diagnóstico. Mycobacterium tuberculosis. Soro.

\section{Abstract}

\section{Biomarkers of tuberculosis: a literature review}

Tuberculosis is a mycobacterial infection commonly caused by the etiologic agent Mycobacterium tuberculosis and likewise by other bacteria of the genus Mycobacterium. Although well documented, more than a century after its discovery it is acknowledged as the deadliest infectious disease in the world. It also configures an important socioeconomic struggle, especially affecting the poorest sections of the society and severely compromising their productive capacities. The standard diagnostic methods for the disease are smear microscopy and culture with recently adopted rapid molecular tests, all of them with important limitations such as the incapacity to discriminate between cases of active and latent tuberculosis, variable sensitivity, and inability to provide prognostics. The present literature review attempted to elucidate the current advances in the biomarkers of the infection in the last 5 years applying the ELISA method. Evidence presented by the studies and the diagnostic performances reached in each context were verified and correlated. An evident heterogeneity in the immunological responses between populations and individuals was observed, likely as a result of the genetic variability of the pathogen that has intercontinental and regional lineages as well as particular differences in the expressions of some biomarkers, either by 
genetic variables or even other underlying diseases; homology of the antigens investigated with other species of bacteria was also problematic. It is clear that particular genetic issues of populations and the infectious agent itself need to be better examined in these studies in order to achieve a sufficiently sensitive and specific serological profile for screening and diagnosis of those patients.

Keywords: Biomarkers. Diagnosis. Mycobacterium tuberculosis. Serum.

\section{Introdução}

Com registros em diferentes épocas, civilizações e contextos, a tuberculose (TB) está presente há milhares de anos como um obstáculo constante na história humana. Peste branca, tísica, mal do rei, escrófula, suas alcunhas são numerosas e peculiares, tal como as formas de tratamento anteriores a era dos antibióticos, produtos de centenas de anos de tentativas (RIVA, 20I4).

A princípio, no período helenístico, médicos romanos sugeriam que os pacientes fizessem uma dieta com grande consumo de leite, descansassem e se nutrissem melhor, fizessem uma "troca de ares". Na Idade Média e Renascença ocorreu a popularização do "toque do rei", que consistia de um ritual em que o rei tocava o doente e ao monarca era atribuída a cura, legitimando o direito divino em governar vigente no contexto desta época (DANIEL, 2006).

No que compreende o século XVIII e início do XIX não houve grandes avanços, apenas o emprego de novos compostos químicos e até mesmo de métodos invasivos e desagradáveis, como sanguessugas. Porém, os sanatórios, criados neste mesmo período, obtiveram considerável sucesso utilizando a abordagem dos médicos romanos: descanso, boa nutrição e consumo de leite (MURRAY; SCHRAUFNAGEL; HOPEWELL, 20I5).

A etiologia da doença só veio a ser esclarecida na segunda metade do século XIX, em I882, pelo médico alemão Robert Koch, que trouxe o Mycobacterium tuberculosis $(M t b)$ ao conhecimento da comunidade científica (DANIEL, 2006). Nos anos seguintes, com o advento da Imunologia, a tuberculina foi desenvolvida, bem como a vacina Bacilo Calmette-Guérin (BCG), todavia a tuberculina apresentava limitações, enquanto a BCG não se mostrou efetiva para a TB pulmonar em adultos (FOGEL, 20I5).

Findando a segunda guerra mundial e décadas posteriores, a indústria farmacêutica em parceria com outras entidades científicas lançou fármacos eficientes contra a doença utilizados até o presente, como a isoniazida e a rifampicina, dando novas perspectivas a pacientes e profissionais (ISEMAN, 2002). Contudo, a TB ainda viria a ser uma questão com a epidemia do Vírus da Imunodeficiência Humana (HIV) no início da década de 90 , sendo declarada em 93 pela Organização Mundial da Saúde (OMS) como uma "emergência global" (OMS, 1994).

Tal qual, hoje, a TB configura problema de saúde pública no Brasil e no mundo, é uma das dez causas principais de morte e líder enquanto um único agente infeccioso - supera o HIV e o Plasmodium da Malária. Segundo levantamento da OMS compreendendo o ano de 20I7, é estimado que 10 milhões de pessoas tenham desenvolvido a doença, com I.3 milhões de mortes por TB entre pessoas com sorologia negativa para o HIV e 300 mil mortes de pessoas HIV/TB (coinfecção por Mycobacterium tuberculosis e Vírus da Imunodeficiência Humana), sendo a causa líder de morte entre esses indivíduos. Julga-se ainda 1.7 bilhões de pessoas, $23 \%$ da população humana, como potenciais portadoras da Infecção Tuberculosa Latente (LTBI) (OMS, 20I8).

A tuberculose droga resistente (TB-DR) também segue como uma questão no controle e combate à doença, com 558 mil casos registrados resistentes a rifampicina - a droga mais eficiente de primeira linha -, aproximadamente $82 \%$ desse total identificados como tuberculose multidroga resistente (TB-MDR). Estimados ainda entre os casos de TB-MDR 8.5\% como tuberculose extensivamente droga resistente (TB-XDR), um dado ainda mais preocupante (OMS, 20I8).

No Brasil as informações de que se têm conhecimento desenham conjuntura semelhante a global. De acordo com dados do Ministério da Saúde, em 2017 no país foram registrados 69.569 novos casos de TB e 13.347 casos de retratamento - com Porto Alegre integrando o primeiro lugar em proporções de retratamento, uma informação bastante verossímil com a realidade de outros dados que também colocam a cidade como uma das líderes em abandono do mesmo (SECRETARIA DE VIGILÂNCIA EM SAÚDE, 20I8).

A TB transcende o campo da saúde pública, extrapolando como um problema socioeconômico consternador, pois se desenvolve mais facilmente na pobreza, assim como a gera; pessoas pobres têm cinco vezes mais chances de contraí-la. Entre as doenças comunicáveis, é que a mais mata no grupo de 15 a 49 anos, quando humanos são mais produtivos; soma o terceiro maior número de DALYs (Disability Adjusted Life Years - Anos de 
vida perdidos ajustados por incapacidade), ultrapassada pela Malária e o HIV, respectivamente. Cabe também notar que se agrava em circunstâncias de má nutrição, tabagismo, uso de álcool e diabetes (OMS, 20I8).

Ainda que nestes mais de 100 anos o teste de baciloscopia tenha sido um método valioso para o diagnóstico da TB, sua sensibilidade oscilante é preocupante - e por vezes o teste é inviável em razão da natureza da amostra necessária: o escarro. A cultura, alternativa mais sensível, igualmente apresenta restrições, a começar pelas semanas (meses) que seguirão até a obtenção de um resultado conclusivo (CHADHA et al., 20 I8; PARSONS et al., 20l I). Os métodos moleculares também possuem limitações importantes, a despeito de detectarem resistência a antibióticos específicos, não diferenciam bacilos vivos de mortos, assim não sendo úteis para indicar a gravidade do curso da doença (OMS, 20I8).

No presente, o único teste rápido endossado pela OMS para TB ativa é o Xpert ${ }^{\circledR}$ MTB/RIF assay (Cepheid, USA), uma opção significativamente mais satisfatória e precisa que a baciloscopia, testando simultaneamente a presença de $M t b$ e a resistência para rifampicina, porém não utilizado de forma ampla devido seu alto custo (HSIANG et al., 20 I6; PURI et al., 20 I6). Para LTBI é aprovado o teste da tuberculina e o Interferon Gamma Release Assay (IGRA), contudo nenhum é considerado padrão ouro para o diagnóstico desse subquadro da TB e possuem muitos contrapontos; cabe ainda notar que a tuberculina é um teste significativamente mais barato e simples (SHARMA et al., 2017).

Apesar da facilidade na obtenção de amostra quando comparado ao escarro da baciloscopia, em virtude dos seus resultados inconsistentes (STEINGART et al., 20I I) a pesquisa de biomarcadores pelos testes sorológicos não são recomendados pela OMS para o diagnóstico da Tuberculose Pulmonar Ativa (PTB). Porém, é extremamente importante que estudos nesse campo sigam, não só em vistas de um futuro teste sorológico efetivo, mas também subprodutos importantes da pesquisa como o melhor entendimento das relações $M t b$-hospedeiro e os feedbacks imunológicos em populações humanas sob diferentes quadros patológicos e outras condições particulares.

Biomarcadores são objetos mensurados e avaliados como indicadores de processos fisiológicos, patogênicos ou de resposta a uma intervenção terapêutica. São úteis pela sua versatilidade na clínica, sendo utilizados como um instrumento diagnóstico, informativos do estágio de determinada patologia, ferramentas de prognóstico ou ainda para monitoramento de resposta a uma intervenção (ATKINSON et al., 200 I). Um exemplo do que é utilizado atualmente no campo da TB seria a pesquisa do IFN- $\gamma$ pelo IGRA; a presença e quantidade ou ausência do Bacilo de Koch na baciloscopia. Em ambos os casos um biomarcador distinto e com características particulares estaria sendo investigado e avaliado para interpretação do quadro do paciente.

O Enzyme-Linked Immunosorbent Assay (ELISA) é um teste diagnóstico fundamentado nas ligações não covalentes antígeno-anticorpo em microplacas desenvolvidas para suporte da reação, havendo a atividade de uma enzima que, em caso da presença da biomolécula complementar, geraria um sinal interpretado como cor - com pequenas variações neste processo a depender do protocolo desenvolvido, mas que não alteram seu princípio. Conhecido por sua alta especificidade e sensibilidade o ELISA pode ser adequado a rotinas automatizadas; adaptável a diferentes protocolos; seu uso é amplo nas áreas de diagnóstico e pesquisa; apresenta boa reprodutibilidade; custo-efetivo e não exige a infraestrutura complexa necessária a realização da baciloscopia e cultura para TB (SECRETARIA DE VIGILÂNCIA EM SAÚDE, 2008; HOSSEINI et al., 2018). Embasado por tais características flexíveis, histórico proeminente na área da medicina laboratorial e a capacidade robusta para grandes rotinas, foi a metodologia escolhida para que seu papel na busca de biomarcadores da TB seja avaliado.

Isto posto, o presente trabalho objetiva verificar estudos recentes que empregaram o método ELISA na pesquisa de biomarcadores da TB utilizando o soro desses pacientes. Igualmente ponderar sobre estas moléculas e seu papel no curso da doença conforme os diferentes contextos relatados pelas pesquisas aqui revisadas.

\section{Materiais e Métodos}

Trata-se de um estudo qualitativo de revisão narrativa da literatura realizado na base de dados eletrônica PubMed. Buscou-se pelas palavras chave: Biomarkers; Diagnosis; Mycobacterium tuberculosis; Serum. Foram selecionados artigos que constassem os termos pesquisados no seu título ou próprias palavras chave; escritos em inglês; com assunto principal limitado a Tuberculose Pulmonar em suas diferentes condições (ativa, latente, associada ao HIV, droga resistente e em tratamento) e que utilizassem o método ELISA na exploração ou validação de biomarcadores sorológicos para o diagnóstico e/ou acompanhamento

Machado e Ermes | Rev. Elet. Cient. da UERGS (2019) v. 5, n. I, p. 27-46 
da doença. O tipo de estudo selecionado (caso controle, ensaio clínico, estudo de coorte, etc.), bem como o aspecto clínico (diagnóstico, predição, terapia, etc.) explorado pelo mesmo, seguiu critério abrangente, a fim de contribuir com a confiabilidade dos resultados deste trabalho revisando uma gama considerável de pesquisas acerca do tema.

Não foram aceitos artigos disponíveis em outras línguas que não o inglês; estudos realizados exclusivamente com animais; artigos que possuíam como tema principal outra modalidade de TB que não a pulmonar, seja por não a citarem no material ou por ser tratada em segundo plano; análises feitas com amostras que não exclusivamente o soro; pesquisas realizadas com outros métodos sorológicos que não ELISA em seus protocolos convencionais (direto, indireto, sanduíche, competitivo).

Posteriormente, foi efetuada leitura integral dos trabalhos que contemplaram as especificações detalhadas acima. Observando sua metodologia (país, população, métodos laboratoriais empregados), resultados (padrões de cada biomarcador em cada âmbito descrito) e discussão (o que os dados obtidos refletem na concepção dos autores) para análise dos mesmos. Realizando correlação entre esses artigos e experiências prévias da literatura quando cabível, sendo estas empreendidas em contexto da tuberculose ou não. A análise deste trabalho foi realizada através de compilação das informações em Word ${ }^{\circledR}$ e tratamento em Excel ${ }^{\circledR}$ na versão do Office ${ }^{\circledR} 2016$, dispensando testes estatísticos para análise de significância.

\section{Resultados e Discussão}

\section{Caracterização da amostra}

A partir dos parâmetros traçados na metodologia chegou-se a um número final de 22 artigos dos últimos 5 anos (Figura I). Foram revisados estudos de II países diferentes (Figura 2) abrangendo 4 continentes, com maior número de trabalhos na China. O montante de trabalhos chinês se encontra dentro do esperado, pois dados figuram o país em três listas preocupantes: alta carga de TB, alta carga de associação TB/HIV (Coinfecção por Mtb e HIV) e alta carga de TB-MDR (OMS, 20I8).
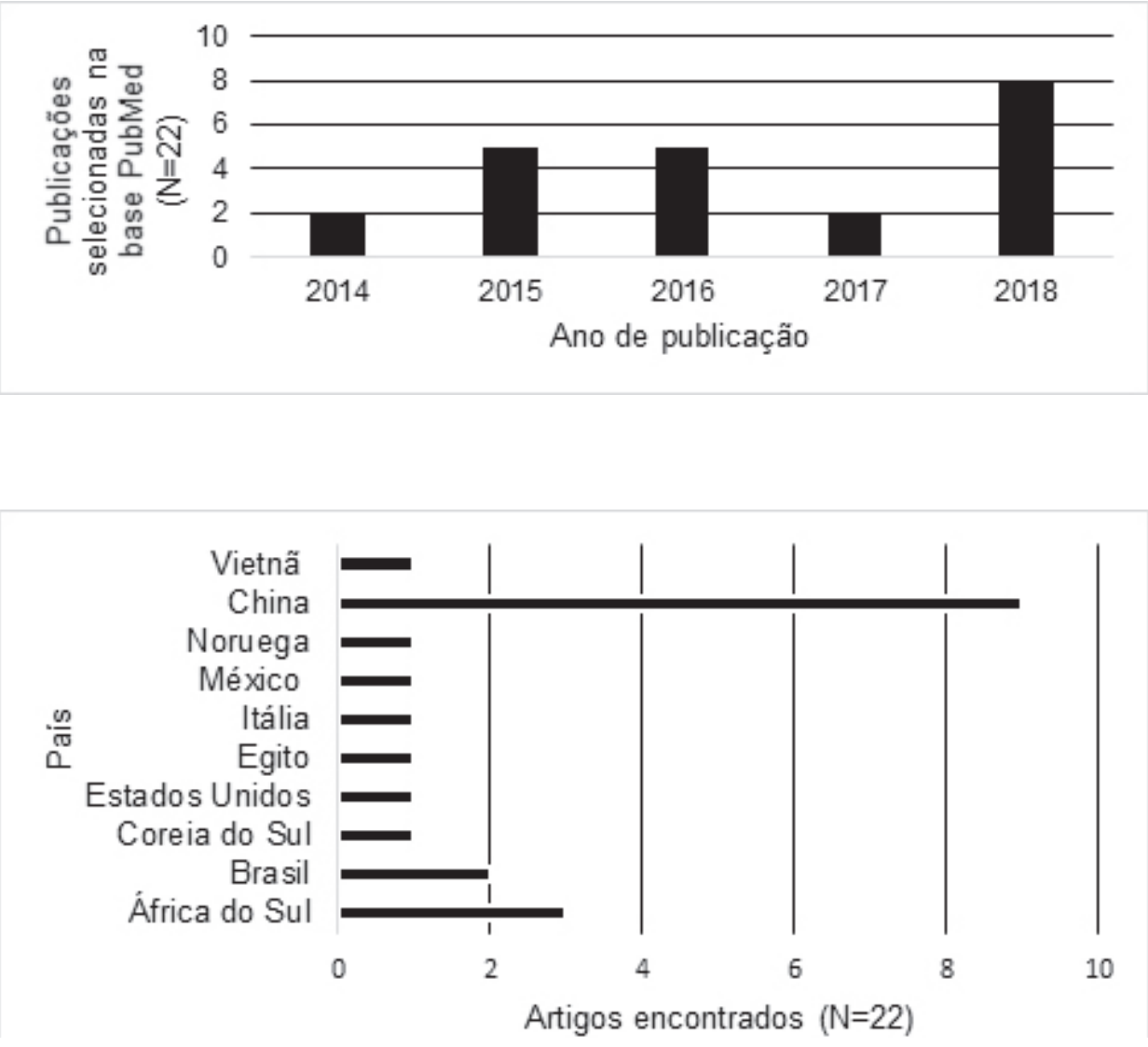

Figura I

Distribuição de artigos encontrados por ano da publicação. 


\section{Biomarcadores para diagnóstico da doença}

Em uma pesquisa chinesa, a partir de análises proteômicas um perfil de reatividade dos anticorpos (Ac) Imunoglobulina G (IgG) e Imunoglobulina M (IgM) para milhares de antígenos (Ag) do Mtb foi gerado. Com base neste perfil os Ag Rv2026c e Rv242 Ic (ambos p < 0.000 I nos ensaios proteômicos para os dois Ac) foram selecionados para validação na metodologia ELISA, chegando a uma sensibilidade de $82.5 \%$ e especificidade em 88.12\% num modelo que combina os biomarcadores IgG anti Rv2026c e Rv242/c, IgM anti $R v 242$ Ic - visto que individualmente suas sensibilidades eram bastante deficientes. Não foram encontradas diferenças estatisticamente significantes entre as metodologias aplicadas (CHEN et al., 20I8b).

A resposta humoral se mostrou distinta entre os sexos, com mulheres apresentando uma reatividade maior que os homens, achado que os autores sugerem estar relacionado as maiores taxas de TB nos últimos (OMS, 20I8), conferindo as mulheres uma maior proteção a infecção. Dados conflitantes foram encontrados no que tange a reatividade dos Ac e sua relação com a gravidade da doença, contrariando pesquisas anteriores (KUNNATH-VELAYUDHAN et al., 20I0; NIKI et al., 20I5) que reportavam correspondência entre as variáveis.

Apenas os níveis de lgG contra o Ag Rv2026c apresentaram associação com a carga bacilar. Nenhuma ligação significativa foi encontrada entre a reatividade dos Ac e lesões cavitárias da TB (CHEN et al., 20 I8b).

Mesmo com resultados consideráveis para os biomarcadores apresentados, o estudo possui limitações no número e diversidade de sua amostra ( 20 indivíduos chineses TB ativa), não sendo o ideal para validar anticorpos - biomarcadores que refletem respostas tão heterogêneas. Seus critérios de exclusão também são discutíveis, pois descartam pacientes importantes na epidemiologia da TB, como por exemplo, incluindo, mas não limitado a indivíduos $\mathrm{HIV/TB}$, uma população extremamente importante em números de incidência e prevalência (OMS, 20I8).

Cao et al. (2018) igualmente triando antígenos por análises proteômicas, pesquisou a reatividade do anticorpo lgG a proteínas específicas do Mtb em soro de pacientes, encontrando, entre outros cinco, os mesmos dois biomarcadores citados por Chen et al. (2018b). Os resultados obtidos pela proteômica também foram validados com o ELISA, entretanto a performance dos analitos individualmente permaneceu similar, obtendo uma substancial melhora com sua combinação apresentando sensibilidade e especificidade acima de $90 \%$.

Os resultados desses trabalhos precisam ser melhor averiguados, pois ambos realizaram seus estudos em populações chinesas, um cenário endêmico para a TB. Assim como o emprego destes biomarcadores em uma amostra maior e presentes indivíduos HIV/TB e outras comorbidades relevantes.

Zhang et al. (2014) avaliou as respostas de lgG para os antígenos Alvo antigênico secretado primariamente de $6 \mathrm{kDa}$ (ESAT-6), Filtrado proteico de cultura de $10 \mathrm{kDa}$ (CFP-I0), Ag85B (ou MPT59 em alguns trabalhos), Hspl6.3 (também referido como proteína de $16 \mathrm{kDa}$ ) e a proteína de fusão Ag85B-Hspl6.3 em pacientes diagnosticados com PTB e LTBI. O propósito na escolha destes antígenos se fundamenta na sua expressão em diferentes estágios do $M t b$, sendo o Hspl 6.3 um antígeno de latência e o restante expressos em fase ativa.

Ag85B-Hsp 16.3/ESAT-6 foram, em associação, os antígenos mais precisos na sorologia de pacientes PTB, enquanto Hsp 16.3/ESAT6 os mais adequados em indivíduos LTBI. Ambos estes perfis sorológicos com sensibilidades variando entre $83 \%$ e $93 \%$ e especificidades acima de $90 \%$ (ZHANG et al., 20I4).

Estas performances foram testadas novamente em rotina, realizando triagem sorológica em 60 doadores de sangue, atestando reagente para 25 deles, sendo 6 destes pacientes PTB e 15 LTBI diagnosticados posteriormente pelo IGRA. Esses resultados sem dúvida trazem respaldo para o modelo pesquisado e seu potencial para triar pacientes em aleatoriedade, especialmente se tratando de doações de sangue, onde a sorologia precisa ser, acima de tudo, sensível.

A pesquisa de anticorpos se mostrou pouco interessante também nos esforços de Ren et al. (20I8).

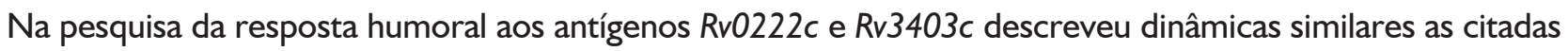
anteriormente em pacientes humanos (sensibilidade e especificidade no intervalo de $70 \%$ a $80 \%$ individualmente, melhorando com a união dos analitos, porém com progresso pouco expressivo).

A resposta mediada por lgG tende a receber maior atenção em grande parte dos estudos, contudo o feedback de outros isótipos também é descrito como útil para diagnóstico sorológico em outras experiências. Um trabalho sul-africano analisou a Imunoglobulina A ( $\lg A)$ e $\lg M$ contra $10 \mathrm{Ag}$ distintos do Mtb. Sendo estes: Lipoarabinomanana (LAM), 7 Ag micobacterianos proteicos (ESAT-6, Tiol peroxidase (Tpx), Proteína

Machado e Ermes | Rev. Elet. Cient. da UERGS (2019) v. 5, n. I, p. 27-46 
de ligação a fosfato I (PstSI), Alanina Desidrogenase (AlaDH), MPT64, proteínas de 16 kDa (também referido na literatura como Hsp l6.3) e 19 kDa (p I9)) e 2 combinações de Ag (TUB (PstSI, 16 kDa, APA), TB-LTBI (Tpx, LI6)) (AWONIYl et al., 20I7).

As duas performances individuais mais eficientes na distinção de casos de TB e outras doenças respiratórias (ORD) foram dos biomarcadores anti- 16 kDa IgA e anti-MPT64 IgA. Esses Ag consistem de subterfúgios para sobrevivência do Mtb em períodos de quiescência e é possível pressupor que trabalhem de uma forma quase sinérgica permitindo a sobrevivência do patógeno dentro de macrófagos, - este achado em linhagem celular monocítica animal - enquanto inibem sua apoptose (WANG et al., 2014; YUAN et al., 1998; YUAN; CRANE; BARRY, 1996).

Ambos exprimiram sensibilidades e especificidades $\geq 90 \%$, o que em si os qualifica para triagem clínica da TB, ainda que o tempo consumido na preparação de um ELISA não seja ideal para triagem (OMS, 20I4). Contudo, como foi reconhecido pelos autores, a pesquisa trata-se de um simples estudo piloto que necessita de futura validação mais cuidadosa. Não apenas seu número amostral é restrito, mas igualmente a população em análise.

Houve também capacidade de discriminação entre pacientes TB e LTBI por parte dos mesmos analitos supracitados, o que destaca suas capacidades diagnósticas. Não obstante, em perfis sorológicos utilizando múltiplos biomarcadores a acurácia para distinção tanto no contexto TB vs. ORD como TB vs. LTBI foi significativamente melhorada, alcançando valores próximos a 100\%. Todavia, volta-se ao ponto das limitações inerentes ao delineamento do trabalho, carecendo estudos de maior proporção para fundamentar (ou não) seus dados (AWONIYl et al., 20I7).

Ainda assim, com os resultados obtidos torna-se perceptível a importância da avaliação de outros isótipos de imunoglobulinas (lg). Em particular a lgA, que foi classificada pelos autores como bastante precisa, conferindo com ensaios anteriores empregando o ELISA em soro de indivíduos adultos (BAUMANN et al., 20I4; LEGESSE et al., 20I3).

A despeito do que foi referido por Awoniyi et al. (2017), Takenami et al. (2016) reportou resultados parcialmente divergentes no que corresponde ao valor diagnóstico da lgA, porém relativo a outro Ag, a proteína Mammalian cell entry IA (Mce IA). Descrita como um mecanismo virulento importante envolvido na invasão e manutenção da infecção em macrófagos, esta proteína é regulada pelo gene Rv0169/mcelA, o qual, quando com o operon desregulado, promove organizações aberrantes do granuloma e uma série de modulações nas células imunes que comprometem suas capacidades de resposta (SHIMONO et al., 2003; SRIVASTAVA et al., 2007; UCHIDA et al., 2007).

Similar ao trabalho anterior, este estudo brasileiro mensurou a resposta humoral utilizando os mesmos três isótipos de $\lg (\lg A$, $\lg G$, $\lg M)$, evidenciando qualidades de resposta claramente distintas entre pacientes TB não tratados e controles para todos esses isótipos previamente mencionados $(p<0.000 \mathrm{I})$. Não obstante, houve significância estatística da IgG quando pareada com pacientes que apresentaram lesões cavitárias no raio $X$ de tórax $(p=0.046)$, associação ausente nos outros isótipos. A IgG também foi a mais eficiente na identificação de pacientes TB, com sensibilidade de $79.5 \%$ e especificidade de $84.4 \%$, inclusive abrangendo o diagnóstico de 10 indivíduos negativos em baciloscopia.

Outra discrepância, não apenas para com o estudo de Awoniyi et al. (2018) como diversos outros revisados no presente trabalho, é do insucesso na combinação de biomarcadores, a fim de agregar maior valor diagnóstico ao modelo. Infelizmente a união dos testes das Ig não acrescentou aos testes considerados positivos (TAKENAMl et al., 20I6).

Apesar das numerosas discordâncias, o relato deste trabalho brasileiro não desvalida de forma alguma as evidências expostas por Awoniyi et al. (2017). Pelo contrário, acaba por expor a inquestionável forma heterogênea com que indivíduos e populações reagem ao patógeno, o qual também possui mecanismos complexos e variados para a administração da sua replicação e transmissão. Ademais, os estudos partilham de escopos similares com relação a sua amostra e tempo de monitoramento dos pacientes, tão logo sofrendo limitações semelhantes.

Prosseguindo com outro estudo brasileiro a respeito da pesquisa de lg como biomarcador, Mattos et al. (2016) pesquisou as respostas da Imunoglobulina G subclasse I (IgGI) frente a Ag fase dependentes do Mtb em três momentos: antes, durante e depois do tratamento anti TB. Ag de fase ativa de crescimento (Proteína de fusão ESAT-6-CPF-I0, Rv07I 7 e Rv3353), Ag de latência (proteínas reguladas pelo protocolo genético de Regulação de sobrevivência em Dormência (DosR): Rv1733, Rv1737, Rv2628 e Rv2029) e fatores promotores de reanimação (Rpf) (Rv0867 e Rv2389), foram os analitos monitorados nos três grupos do estudo. 
Rv07I7, Rv3353, Rv1733, Rv2628, Rv2029 e Rv0867 apresentaram especificidades e sensibilidades superiores a $80 \%$, sendo todos estes igualmente ou mais específicos que o biomarcador ESAT-6-CPF-I0, este na condição de controle positivo das análises em virtude da sua imunodominância já conhecida. Destaca-se a performance individual do analito RvI733, uma potencial proteína transmembrana, bastante imunogênica em populações africanas (BLACK et al., 2009; SUTHERLAND et al., 20I3) e já utilizada para predição de pacientes LTBI com eficiência (SERRA-VIDAL et al., 20I4).

O Ag RvI 733 exibiu $88.2 \%$ em sensibilidade e $95.7 \%$ em especificidade em uma população considerada portadora de infecção ativa do Mtb, o único a se mostrar integralmente superior a ESAT-6-CPF-10. Esse comportamento é discordante com a maioria das pesquisas em que é citado aparecendo como um antígeno bastante responsivo em pacientes LTBI (BLACK et al., 2009; SERRA-VIDAL et al., 20I4; SUTHERLAND et al., 20I3). Mesmo assim há registro de performance semelhante (KASSA et al., 20I2), é notável que também seja em uma coorte bastante restrita, assim como a do estudo, sendo razoável apontar que suas evidências precisem ser melhor corroboradas em um estudo maior. Assim como logicamente também levanta a questão das diferenças genéticas entre cepas e até mesmo entre as populações humanas observadas nessas várias pesquisas.

Thuong et al. (20l6), investigaram níveis séricos da Granulisina (GNL) - um dos grânulos citotóxicos secretados por subpopulações de linfócitos no combate a patógenos intracelulares - em trabalhadores da área da saúde, atuantes de centros de atenção específicos para TB no Vietnã. A partir dos resultados dos IGRA os grupos foram dicotomizados em positivos e negativos, com as concentrações da GNL diferindo significativamente entre eles.

Considerando os trabalhadores positivos para IGRA como LTBI, os autores observam a correlação negativa entre o IFN- $\gamma$ e a GNL nesse estágio da infecção (THUONG et al., 2016). Os mecanismos para essa apresentação da molécula são bastante vagos, mas os autores propõem a hipótese de que o sequestro e acúmulo de células produtoras da GNL ao redor de granulomas possa ser uma das explicações, bem como o consumo da molécula pela imunidade efetora que estaria agindo no combate ao Mtb. Porém, há registro de baixa expressão da GNL no local da infecção (ainda que em casos crônicos), isso se transfere até mesmo a nível de proteínas e transcrição, o que pode sugerir que há falha na estabilidade desse biomarcador no combate ao patógeno (ANDERSSON et al., 2007).

Cabe ressaltar que o artigo em questão efetuou análise de três genótipos (CC, CT, TT) do Single Nucleotide Polymorphism (SNP) rs I I I 27 da GNL, encontrando discrepâncias no que se refere ao conferido e a expressão de RNA mensageiro (mRNA), entretanto o genótipo não foi associado com o status positivo para o IGRA, apenas níveis circulantes de GNL foram negativamente associados ao IGRA. Por conseguinte, induzindo ao entendimento de que a redução deste biomarcador seja uma consequência inicial de um quadro infeccioso incipiente (LTBI) e que tende a persistir - dado que pacientes TB ativa inicial e relapsa também apresentam níveis séricos diminuídos (PITABUT et al., 20I I) e após a terapia concentrações comparáveis a controle (SAHIRATMADJA et al., 2007).

Pesquisadores italianos também estudaram o potencial diagnóstico de outra molécula citotóxica: a Granzima A (GUGGINO et al., 20I5). Por se tratar de um estudo piloto, a amostra do artigo é bastante pequena e seus grupos bastante restritos, mas nos pacientes controle e considerados afligidos por infecção pulmonar pneumocócica as concentrações do analito se mostraram nulas. Enquanto isso, os níveis da Granzima A foram significativamente menores em pacientes PTB comparados aos LTBI, assim como o descrito na GNL por Thoung et al. (20l6), contudo aqui não foram encontradas correlações entre as concentrações de IFN- $\square$ e a molécula citotóxica em estudo.

No artigo são relatadas sensibilidade de $29.4 \%$ e especificidade de $94.7 \%$ na discriminação entre casos TB e LTBI. Sua alta especificidade é um ponto forte importante, mas a sensibilidade do teste é extremamente baixa para qualquer aplicabilidade clínica (OMS, 20I4).

Logicamente esses resultados necessitam de uma validação maior, não apenas pelo tamanho da amostra, como também a inclusão de indivíduos HIV/TB, tendo em vista maior controle sobre a infecção e potenciais interferências nos níveis de moléculas citotóxicas dos linfócitos (PITABUT et al., 20I3). Considerando-se tudo isso é razoável afirmar que as flutuações das moléculas citotóxicas em quadros tanto LTBI como PTB precisem ser melhor estudadas, do mesmo modo que os genótipos associados a diferentes expressões dessas proteínas.

No México, pesquisadores dosaram os biomarcadores do hospedeiro Monoquina Induzida por IFN- $\gamma$ 
(CXCL9/MIG), Receptor do Ativador de Plasminogênio tipo uroquinase solúvel (suPAR) e sCDI4; também mensurando a resposta de Ac aos peptídeos imunodominantes de Ag específicos do Mtb: PI2033, PI2034, PI 2037 (peptídeos do Alvo antigênico secretado primariamente de 6 kDa (ESAT-6)) e P29878 (peptídeo do Ag Ag85A) (LÓPEZ-RAMOS et al., 20I8).

Com exceção a suPAR, todos os marcadores se mostraram significativos entre o grupo PTB e os dois restantes (indivíduos controle e considerados TB latente). Devido este resultado, maiores análises para discriminação e capacidade diagnóstica individuais de cada analito foram realizadas, apontando o biomarcador sCDI4 e o peptídeo PI 2037 como os mais eficientes num modelo diagnóstico seriado. Em combinação as duas moléculas apresentam $92 \%$ em sensibilidade e $91 \%$ de especificidade, valores quais os autores argumentam não serem atingidos em testes convencionais da TB, especialmente em um teste tão barato como 0 ELISA e em modelo seriado (LÓPEZ-RAMOS et al., 2018).

Mesmo com números tão promissores, os resultados do trabalho precisam ser melhor explorados em uma amostra numericamente maior e geograficamente mais diversa, visto que a única população avaliada no estudo foi a mexicana. Sendo uma análise restrita, isso pode acarretar em discrepâncias devido diferentes expressões dos biomarcadores dado a genética populacional e inclusive aos genótipos distintos do próprio patógeno, extensamente diversos (COSCOLLA; GAGNEUX, 20I4).

Luo et al. (2017) também investigaram a resposta a peptídeos imunodominantes, especificamente dos Ag Rv03 I0c e Rv1255c, num estudo envolvendo pacientes positivos e negativos para baciloscopia. Outros três Ag: ESAT-6, CFP- 10 e Rv3425 foram utilizados como controles positivos, por se tratarem de proteínas já bastante utilizadas na sorologia da TB. Os títulos de lgG foram comparados entre os grupos, mostrando diferenças significantes entre todos os Ag e os grupos de pacientes TB e controles, porém nenhuma relevância entre os grupos positivo e negativo para baciloscopia.

Individualmente $R v / 255$ c se mostrou mais eficiente para o grupo baciloscopia negativa, com sensibilidade de $73.84 \%$ e especificidade em $\mathbf{8 2 . 8 9 \%}$. Em contrapartida, no grupo positivo, os Ag Rv03 IOc e Rv3425 evidenciaram maior valor diagnóstico em conjunto, atingindo sensibilidade de $87.3 \%$ e especificidade de 73.68\% (LUO et al., 2017). Ambos os perfis, entretanto, não cumprem os padrões clínicos mínimos para diagnóstico ou triagem convencionados (OMS, 2014).

Demais trabalhos também realizaram suas análises de biomarcadores antigênicos na pesquisa de peptídeos imunodominantes. A escolha parte do princípio da melhoria da sensibilidade - sendo uma abordagem bastante eficiente nesse sentido - e de que algumas sequências de aminoácidos parecem ocultar epítopos importantes (AFZAL et al., 20I5; FENG et al., 20I3).

Outra pesquisa chinesa, realizada por Chen, et al. (2016), também procurou esclarecer os papéis de quimiocinas e proteínas específicas no curso da TB. O ELISA foi aplicado na qualidade de validação para outra metodologia multiplexada de uso exclusivo em pesquisa. As quimiocinas Interleucina 8 (IL-8/CXCL8), MIG, 1309 (também referida na literatura como CCLI), Eotaxina 2 (CCL24) e a proteína Molécula de Adesão Intercelular-I (ICAM-I) tiveram suas capacidades diagnósticas avaliadas em três situações: PTB, LTBI e durante o tratamento - contudo este acompanhamento seriado não foi validado pelo ELISA, não cabendo observações.

IL-8, MIG, e I-309 manifestaram expressão exacerbada em pacientes PTB em comparação com controles $(p<0.05)$. A MIG destacou-se por também se mostrar relevante em pacientes com ORD utilizados na pesquisa como segundo controle - este grupo incluía pacientes com pneumonia crônica e câncer de pulmão - de qualquer forma a junção dos biomarcadores não se mostrou satisfatória e nenhum deles foi suficientemente específico, o que é compreensível pelas suas condições de quimiocinas pouco características no curso de processos infecciosos.

A CCL24, ICAM-I e MIG exibiram significância em pacientes considerados LTBI contrapostos aos controles $(p<0.0 \mathrm{I})$, conquanto, ainda que biomarcadores sensíveis, não justificam sua escolha para modelo diagnóstico visto especificidade baixa. Cabe reparar a presença da CCL24 como um analito expressivo em quadros tuberculosos, posto que age sobre eosinófilos, basófilos (MENZIES-GOW et al., 2002) e a subpopulação de linfócitos Th2 (SALLUSTO; MACKAY; LANZAVECCHIA, 1997), não exercendo função bem estabelecida em monócitos, o principal tipo celular envolvido na defesa contra o Mtb.

Um ponto não explorado pelos autores e que pode propor um fundamento para a acentuação da CCL24 é o desequilíbrio mencionado pelos próprios na Relação de células T helper tipo I e T helper tipo 2 (Th I/ 
Th2) em favor da Th2 nos pacientes TB (CHEN et al., 2016). Isso já foi descrito anteriormente na literatura como um quadro associado a PTB e até mesmo prejudicial a capacidades dos fagócitos (ASHENAFI et al., 20 I4; HARRIS et al., 2007; LIU et al., 20I8). Parece então haver uma interação importante entre as células Th2 e a CCL24 que merece maior atenção em futuros estudos voltados a patogênese e curso da TB.

O biomarcador Micotiol acetiltransferase (Rv08/9) foi alvo de pesquisa no trabalho conduzido por Zeitoun et al. (2017) em um hospital no Egito, a amostra foi composta por 68 pacientes recentemente confirmados com TB. As mensurações foram feitas com ELISA competitivo e Dot blot (qualitativo), sendo este artigo em especial o único nesta revisão a mostrar diferenças expressivas entre o ELISA e o outro método empregado.

O ensaio Dot blot atingiu $100 \%$ de especificidade, enquanto o ELISA apenas $88.57 \%$. As sensibilidades de ambos os testes foram baixas, mas ainda assim o Dot blot atingiu um valor maior de $64.7 \%$ em comparação ao ELISA, em moderados $54.4 \%$. Combinando os resultados das metodologias uma sensibilidade de $89.7 \%$ era alcançada - solução eficiente, no entanto potencialmente custosa em uma rotina (ZEITOUN et al., 20I7).

Outro contraste bastante chamativo foi no tocante ao soro de pacientes HIV/TB, pois dos 5 presentes no estudo, em absoluto, nenhum se mostrou reagente para o analito no ELISA competitivo, porém todos foram considerados reagentes no ensaio Dot blot. Lamentavelmente este resultado é negligenciado pelos autores durante sua discussão, não sendo propostas quaisquer hipóteses que possam elucidá-lo (ZEITOUN et al., 2017).

Indiferente às discrepâncias metodológicas, como é citado pelos autores, o Rv08 I 9 é um Ag comum a outras Mycobacterium e Actinobacteria, pois consiste de uma enzima fundamental na produção do micotiol, uma molécula importante nas reações de oxidação nesses microrganismos (FAHEY, 200I). Isto posto, em análise bioinformática foi identificada homologia considerável desta molécula entre os actinomicetos mais próximos do gênero Mycobacterium. Portanto, a partir disso os autores cogitam a hipótese de reação cruza$\mathrm{da}$, uma casualidade importante em testes sorológicos, especialmente competitivos (PARK; KRICKA, 20I3) - como é o caso do realizado no estudo - e também com histórico em outros Ag do Mtb (MAY et al., 2009). Todavia, é uma possibilidade que necessita de maior investigação em pacientes infectados por outros actinomicetos de interesse, um grupo amostral ausente nos ensaios (ZEITOUN et al., 20I7).

No que diz respeito especificamente a pacientes HIV/TB, apenas 2 dos 22 artigos revisados neste trabalho abordam o tema com total atenção. Um destes seria uma iniciativa chinesa, realizada por Chen et al. (20।8a), que trata de métodos proteômicos na pesquisa de um biomarcador sorológico para esses sujeitos TB/HIV.

Comparando o soro de pacientes HIV+ e HIV/TB, os pesquisadores identificaram proteínas muito e pouco expressas nesses indivíduos a fim de avaliar a resposta do hospedeiro nesses dois cenários (CHEN et al., 2018a). A molécula mais expressa nos casos de coinfecção - 4.9x aumentada pelo método proteômico, em comparação a I I.5x no ELISA - foi a endoglina (ENG) $(p<0.005)$, uma proteína receptora transmembrana, coreceptor da citocina Fator de Transformação do Crescimento $\square$ (TGF- $\square$ ), que tem papel na fibrose, regulando proliferação, migração e diferenciação (GOUMANS; LIU; TEN DIJKE, 2009).

Os autores sugerem que essa hiperexpressão possa estar associada a patogênese da TB, mais especificamente a manutenção dos granulomas, que algumas pesquisas mostram se tornarem veículos para a disseminação do Mtb como consequência de nova vasculatura deficiente formada pela angiogênese desregulada (OEHLERS et al., 20I5; POLENA et al., 2016). Ainda que estes estudos não abordem a ENG - e sim o Fator de Crescimento do Endotélio Vascular (VEGF) -, a hipótese adotada pelos pesquisadores é coerente, e com uma futura análise mais criteriosa da manutenção bioquímica-estrutural dos granulomas pode vir a se mostrar correta.

Cabe notar também que há resultados iniciais com tratamento anti VEGF em modelos animais com TB, melhorando a eficácia da antibioticoterapia no microambiente vascular do granuloma por meio de uma circulação eficiente da molécula terapêutica em vasos funcionais (DATTA et al., 20I5). O que respalda ainda mais a questão dos efeitos de uma angiogênese irregular num quadro de TB.

O outro artigo direcionado a pacientes HIV/TB visto nessa revisão investigou as respostas de lgG para os Ag MPT5 I, Malato Sintase (MS), echAl e a proteína de $38 \mathrm{kDa}$ do Mtb nesses indivíduos, particularmente os considerados negativos em baciloscopia, condição de difícil diagnóstico. A pesquisa foi realizada na África do Sul, com amostras locais e de pacientes estadunidenses para controle (SIEV et al., 20I4). 
Como esperado, as respostas para esses $\mathrm{Ag}$ comparadas com as de outras populações em trabalhos prévios foram heterogêneas, até mesmo entre populações dentro da África. Outro ponto importante foi a confirmação de experiências anteriores (GUPTA et al., 20I3; SIEV et al., 20I4) que afirmam que a carga de CD4 não tem correlação clara com a resposta humoral nesses casos.

Os Ag de melhor performance nos grupos foram o MPT5I e o echAl, tendo a MPT5I um alto poder discriminatório entre casos e controles. A performance combinada destas proteínas alcançou $88 \%$ de sensibilidade em pacientes negativos para baciloscopia e cultura, e 100\% em negativos para ambas - ao custo de sua especificidade. Os autores argumentam que mesmo frente a uma especificidade inferior a $50 \%$ como a que foi atingida, altos valores em sensibilidade são clinicamente úteis em determinados cenários de recursos limitados (SIEV et al., 20I4).

Isto é, a partir de evidências suficientes que sustentem a resposta a estes $\mathrm{Ag}$ como um feedback sólido do hospedeiro a existência de infecção pela TB, há oportunidade de evitarem-se tratamentos prolongados desnecessários. Igualmente, identificar casos em que a doença ainda não se desenvolveu, abrindo a perspectiva para intervenções quimioterápicas prematuras. Apesar disso, como bem posto pelos autores, no presente os biomarcadores estudados se encontram a nível de informação adicional como auxílio a métodos diagnósticos comuns, como a baciloscopia e a cultura (SIEV et al., 20I4).

Levanta-se também a possibilidade de que a resposta detectada em indivíduos controle sul africanos $\mathrm{HIV}+$ - porém, sem diagnóstico de $\mathrm{TB}$ - para os $\mathrm{Ag}$ em pesquisa (especialmente a echAl) possa indicar uma resposta sorológica inicial a infecção pelo $M t b$. Isso é cogitado, em suma, por questões epidemiológicas da região aliadas aos resultados do ELISA, mas é uma afirmação de difícil sustentação sem um acompanhamento posterior adequado desses pacientes (SIEV et al., 20I4).

Xu et al. (2014) traçou biomarcadores bastante singulares para o diagnóstico da TB, uma vez que não pesquisou $\mathrm{Ag}$, tampouco $\mathrm{Ac}$, mas sim um perfil proteômico de resposta do hospedeiro frente a infecção. Posterior a identificação e quantificação das proteínas mais abundantes por metodologias proteômicas e análise bioinformática, o estudo utilizou ELISA e Western blot para validação dos seus resultados.

Em ambos ensaios imunológicos empregados as dosagens dos analitos foram correspondentes com as metodologias proteômicas. Comparados pacientes PTB e controles saudáveis, Proteína Ligante do Ácido Hialurônico 2 (HABP2) e CD5 antigen-like (CD5L) se exibiam notadamente aumentadas $(\mathrm{p}<0.000 \mathrm{I}$, $\mathrm{p}<0.0002$, respectivamente); enquanto a Apolipoproteína CII (APOCII) e a Proteína Ligante de Retinol 4 (RBP4) estavam consideravelmente diminuídas (ambas $p<0.000 \mathrm{I}$ ).

Isoladamente as moléculas apresentavam sensibilidades e especificidades bastante modestas, mas unindo-as em um modelo diagnóstico sua bioassinatura oferece sensibilidade de $93.42 \%$ e especificidade de $92.86 \%$ - valores bastante promissores. Em contrapartida esse desempenho diagnóstico repete as mesmas brechas encontradas em outros diversos artigos nesta revisão, pois foi atingido em uma coorte pequena de pacientes, sem grupos ORD para controle, ausência de pacientes HIV, pediátricos e amostras geograficamente restritas - apenas indivíduos chineses.

O comportamento da proteína Cl q do Sistema Complemento durante PTB e LTBI foi analisado em um estudo com amostras intercontinentais de regiões endêmicas e não endêmicas da TB, também envolvendo pacientes com hanseníase, sarcoidose e pneumonia - visto que se trata de um biomarcador inflamatório bastante generalista que requer maior validação. A partir de uma análise combinada envolvendo todos os pacientes TB, grupos controle, LTBI e os pacientes tratados com sucesso o trabalho pode constatar que há um aumento significativo da Clq na PTB ( $p<0.00$ I) (LUBBERS et al., 2018).

A estabilidade da molécula também foi testada em indivíduos antes e após a aplicação da vacina BCG, não indicando variação expressiva, porém o grupo utilizado para esta análise foi tão significante quanto os outros no estudo: apenas 13 indivíduos. Nos pacientes comprometidos pelas outras patologias de base citadas acima também não foram verificadas diferenças significativas comparados a PTB $(p<0.001)$.

Houve uma queda após 6 meses de tratamento $(p<0.00 \mathrm{I})$ em pacientes monitorados da Gambia, oferecendo evidência de que o aumento considerável registrado está relacionado com a fase ativa da doença, não uma predisposição intrínseca do indivíduo. Nota-se que todos esses resultados acordam com relatos anteriores da literatura que aplicaram o ELISA (CAl et al., 20I4; CLIFF et al., 20I3). Contudo o desempenho diagnóstico atingido não foi satisfatório; ainda que muito específica a $\mathrm{Clq}$ exibe sensibilidade muito baixa, falha já presente em métodos atuais para o diagnóstico da TB. 


\section{Biomarcadores para monitoramento da terapia e cura}

Um estudo sul coreano avaliando a resposta inicial ao tratamento da TB com base em dosagens do começo e dois meses após início da quimioterapia, analisou três ligantes da proteína CXCR3, as quimiocinas: CXCL9/MIG, Proteína Induzida por IFN- $\gamma$ I0 (CLCXI0/IP-10) e Quimioatrator IFN-induzido de Célula-T (CXCLII/I-TAC). Sendo relatado correlação entre estas e a resposta rápida ao tratamento dos pacientes $(p<0.01)$, obtendo valores de especificidades $>90 \%$ e sensibilidades de $64 \%$ a $83 \%$. Estes valores foram consideravelmente melhorados com combinações destas moléculas, atingindo $88 \%$ a $93 \%$ em sensibilidade, mas sem maior progresso na especificidade.

Adicionalmente, todos os três analitos observados se mostraram responsivos dentro do que foi considerado uma resposta quimioterápica rápida ou lenta $(\mathrm{p}<0.00 \mathrm{I})$. É sugerido que a ausência de quedas significativas nos primeiros 2 meses indique a necessidade de se prolongar o tratamento, entretanto as evidências obtidas pelos autores são insuficientes para que isso possa ser afirmado com segurança (CHUNG et al., 20I6).

O IFN- $\gamma$, molécula alvo nos testes IGRA, também foi estudado na mesma pesquisa e, corroborando com outros relatos na literatura, não se mostrou útil ao propósito de monitoramento anti TB, sem apresentar significância em qualquer dos grupos (CHUNG et al., 2016). Visto suas flutuações e expressão heterogênea entre pacientes já observadas, é evidenciado um papel limitado do biomarcador neste aspecto (DENKINGER et al., 20I3; LEE et al., 20I5).

Todavia, apesar dos resultados significativos deste trabalho é indispensável notar algumas de suas deficiências e limitações: baixo número de amostras; ausência de um grupo controle com outras infecções para comparação de níveis dos analitos estudados, pois os mesmos se expressam em diversas outras infecções e quadros inflamatórios; acompanhamento limitado de pacientes quais o tratamento falhou; critérios arbitrários e pessoais dos autores utilizados para avaliar tanto a diminuição dos biomarcadores em estudo, considerando uma queda $>20 \%$ como significante, do mesmo modo quanto a divisão de pacientes em "tratamento de sucesso"/"fracassado", dicotomia construída de forma subjetiva na ausência de critérios pré-estabelecidos (CHUNG et al., 2016).

De forma similar um trabalho chinês (TONBY et al., 20I5) pesquisou o comportamento da IP-10 em pacientes em regime quimioterápico. Não é possível avaliar com clareza se os resultados trazem padrões semelhantes ou distintos dos expostos por Chung et al. (2016), devido os critérios particulares adotados por estes citados acima, contudo a IP-I0 permaneceu responsiva a terapia com quedas notáveis no ponto de 8 semanas, assim como a conversão de grande parte dos pacientes em cultura negativa neste período de tempo presente nos dois trabalhos.

O regime quimioterápico reproduzido no estudo foi de 24 semanas e composto pelos mesmos fármacos de Chung et al. (20I6). Relatadas reduções significativas do analito nas primeiras 2 semanas $(p<0.00 \mathrm{I})$, outra queda em 8 semanas $(p<0.00 \mathrm{I})$ e níveis baixos estáveis já em 24 semanas $(p<0.00 \mathrm{I})$. Resultados obtidos a partir de dados da metodologia Dry Plasma Spots (DPS) com amostras mensuradas em ELISA, esta foi avaliada no artigo junto as amostras utilizadas do plasma de tubos (TONBY et al., 20I5).

É importante observar a questão do uso simultâneo no trabalho de duas metodologias distintas sendo dosadas pelo ELISA, com uma boa correlação entre ambas no decorrer do tratamento $(p<0.000 \mathrm{I})$. Essas metodologias seriam o DPS e os típicos tubos de ensaio utilizados em coleta.

Os Dry Blood Spots (DBS) ou DPS - que se diferenciam apenas pelo material estocado - foram criados na década de 60 por Robert Guthrie para diagnóstico de fenilcetonúria em neonatos (GUTHRIE; SUSI, 1963). Tratam-se de filtros para preservação e transporte de analitos do sangue (proteínas séricas, Ac, hormônios, carga genética viral, etc.) em pequenos discos que necessitam de poucas gotas para que a análise seja realizada com eficiência (AABYE et al., 20I2). Suas vantagens principais seriam, como já mencionado, a facilidade para preservação, transporte e a própria coleta.

Especificamente no que concerne os resultados do ELISA, pode-se notar por meio de outros pacientes com diferentes comorbidades que a IP-I0 é muito reativa a eventos imunológicos. Enquanto no restante de casos em que houve melhora progressiva, o biomarcador manteve níveis baixos aliado a resultados negativos na baciloscopia. É considerável observar os dois pacientes com doença de Crohn e um paciente relapso que estava retratando a TB após dois anos do fim da sua primeira quimioterapia - estes indivíduos em especial apresentaram níveis altos persistentes de IP-I0 (TONBY et al., 20I5).

Machado e Ermes | Rev. Elet. Cient. da UERGS (2019) v. 5, n. I, p. 27-46 
Individualmente e em combinação a IP-10 possui outros resultados na literatura quanto a sua utilidade em controle da quimioterapia (HONG et al., 20I4; ZHAO et al., 20I8). De fato, embora o trabalho mostre resultados promissores, o estudo experimenta limitações similares a outros revistos aqui, principalmente no que se refere ao número limitado de pacientes envolvidos, não representativos de sua população.

Em uma investigação estadunidense para monitoramento da antibioticoterapia os analitos dosados pelo ELISA foram: Neopterina, Granzima B, sICAM-I, IP-I0 e suPAR, todos estes indicadores não específicos de inflamação. Os imunoensaios foram feitos com amostras anteriores ao início da terapia e 8 semanas após, com soro de pacientes confirmados com TB por cultura (JAYAKUMAR et al., 20I5).

O objetivo deste estudo foi checar a correlação reportada em experiências anteriores da literatura com os marcadores supracitados, sendo relatado resultados semelhantes para 4 dos 5 biomarcadores pesquisados em ELISA. Em contrapartida houve um achado particular, citando que há divergência nos resultados dos marcadores e deles para com a sua comparabilidade.

Shang et al. (20l8) investigaram o papel da citocina Fator de Inibição da migração de Macrófagos (MIF) associada ao Fator de Necrose Tumoral $\alpha$ (TNF- $\alpha$ ) e IFN- $\gamma$ no curso da quimioterapia em pacientes chineses hospitalizados. Já no período de pré-tratamento os 47 participantes foram dicotomizados em níveis altos (39) e baixos (8) de MIF, com níveis altos desta sendo relacionados ao TNF- $\alpha$.

Posteriormente, em 6 meses de terapia a nova dosagem mostrou níveis reduzidos de todos os biomarcadores $(p<0.01)$ próximos aos dos controles. Em discordância a estes resultados, 6 pacientes que manifestaram TB-DR seguiram com níveis significativamente mais altos do que o restante $(p<0.000 \mathrm{I})$. Com base nas curvas desses analitos é possível traçar uma linha de resposta clara para uma quimioterapia considerada de sucesso, ainda que a reprodutibilidade desses dados precise ser melhor averiguada em virtude não só do tamanho da amostra e doenças de base, como também do período limitado de acompanhamento relatado.

A respeito das doenças de base listadas nos pacientes do estudo, haviam indivíduos com câncer, diabetes, hepatites $\mathrm{B}$ e $\mathrm{C}$ e fumantes com história pregressa. Os autores não refletem as repercussões desses quadros na dinâmica dos biomarcadores pesquisados, o que dificulta maiores conclusões (SHANG et al., 20I8).

A forte correspondência entre MIF e TNF- $\alpha$ pode ser elucidada em razão da ativação causada pela primeira de células mononucleares (linfócitos, monócitos, células dendríticas) e neutrófilos, que posteriormente secretariam TNF- $\alpha$, exacerbando a inflamação. No entanto, a ausência de correlação significante entre MIF e IFN- $\gamma$ não é averiguada com atenção em nenhum momento do trabalho. Este achado pode ser parcialmente explicado pela expressão heterogênea de IFN- $\gamma$ entre indivíduos, como já mencionado previamente, mas é uma consideração que necessita a abordagem mais adequada de métodos moleculares para checar sua veracidade.

Já citada anteriormente, a pesquisa de Mattos et al. (2016) averiguou as respostas da Imunoglobulina G subclasse I frente a $\mathrm{Ag}$ fase dependentes do Mtb em três momentos: antes, durante e depois do tratamento anti TB. Ag de fase ativa de crescimento (ESAT6/CFP-10, Rv07I7 e Rv3353), Ag de latência (proteínas reguladas pelo protocolo genético DosR: Rv1733, RvI737, Rv2628 e Rv2029) e Rpf (Rv0867 e Rv2389), foram os analitos monitorados nos três grupos do estudo.

O relato do artigo pertinente a quimioterapia observa uma queda significativa nos níveis da lgGI para as proteínas ESAT-6/CFP-10, Rv3353, Rv2628, Rv2029 e Rv0867 após 6 meses de tratamento, apresentando concentrações comparáveis as do grupo controle $(p<0.0 \mathrm{I})$. Já com I ano de quimioterapia tinha-se declínio profundo na concentração de $\operatorname{lgGI}$ respectiva para todos os $\mathrm{Ag}$ de interesse, atingindo níveis equivalentes aos do controle. Sendo assim, pode-se concluir que a decaída deste Ac para os alvos em pesquisa sugere um tratamento de sucesso (MATTOS et al., 2016).

Resultados do trabalho relativos a importância da lgGI entre as lg corroboram experiências prévias, as quais também utilizavam o método ELISA e, portanto, justificam sua escolha para mensuração (GUPTA et al., 2005; MATTOS et al., 20 I0). Pesquisas anteriores também reafirmam a importância da análise de Ac na quimioterapia anti TB, inclusive na TB infantil, notando quedas substanciais conforme o estágio do tratamento, ainda que explorando Ag distintos (BAUMANN et al., 20I 3; FUJITA et al., 2005; SIRECl et al., 2007).

Os autores propõem especialmente que o monitoramento da resposta aos Ag Rv I 733, Rv07 I7, Rv3353, Rv2628 e Rv0867 seja relevante para predizer desfechos da quimioterapia. Essa ideia se justifica pela resposta humoral expressiva aos mesmos identificada 3 meses após início do tratamento e que normaliza progressivamente nas terapias de sucesso observadas. Essas flutuações são assumidas como consequentes da liberação de Ag pela morte dos bacilos, graças a efetividade da quimioterapia (MATTOS et al., 2016). 
No entanto, compete destacar novamente o número baixo de amostras desta pesquisa, grupos de 6 meses e I ano de tratamento utilizados para mensuração são compostos por 20 e 6 indivíduos, respectivamente. Não obstante, nenhum dos outros grupos submetidos a análise possui sequer 50 indivíduos e não foram observados pacientes quais a quimioterapia falhou (MATTOS et al., 2016).

Awoniyi et al. (2017), também já mencionado, do mesmo modo acompanhou o curso da doença por meio de títulos dos Ac. Os autores reportaram uma queda significativa nos biomarcadores anti- $16 \mathrm{kDa}$ lgM e anti- 6 kDa IgA após o que foi considerado uma terapia de sucesso.

Apesar disso, citam trabalhos anteriores em sua ponderação que relatam resultados bastante discrepantes (IMAZ; ZERBINI, 2000; LYASHCHENKO et al., 1998) no que se refere a resposta humoral dos indivíduos no curso da quimioterapia. Ambos os trabalhos mencionados para o embasamento dessa linha de raciocínio são relativamente antigos e com as mesmas limitações amostrais recorrentes dos atuais examinados nesta revisão, porém trazem o questionamento se, de fato, as respostas imunes multifacetadas no curso da TB seriam o alvo ideal para o desenvolvimento de um perfil de supervisão do tratamento nesses pacientes.

As observações de Takenami et al. (2016) pertinentes a competência diagnóstica da lgG anti-McelA coincidem igualmente a variabilidade das respostas humorais. Em seu estudo o biomarcador em questão não foi eficiente para o acompanhamento das antibioticoterapias daquela população, pois houve soroconversão em menos de I/3 dos pacientes avaliados no momento de 2 meses. Em contrapartida 20 dos 26 pacientes positivos para a baciloscopia passaram a ser considerados negativos no mesmo período de 2 meses - a microscopia do escarro evidentemente foi a metodologia mais adequada nesse cenário.

Dito isto, se tornam mais uma vez inegáveis os feedbacks consideravelmente distintos nos indivíduos em tratamento. Entretanto, a princípio nenhum dos estudos a avaliar Ig teve presente em sua amostra tratamentos falhos ou relapsos - bem como o período de acompanhamento aos pacientes, que foi bastante restrito em todos -, situação qual há precedência de valor diagnóstico (BHATTACHARYYA et al., 20I4). Ainda que esta conjuntura lamentavelmente não tenha sido retratada em pacientes $T B$, mas sim mas sim infectados pelo protozoário do complexo Leishmania donovani, trata-se de um indício relevante do acompanhamento dos títulos de lg em casos de insucesso terapêutico.

Investigando biomarcadores para cura da TB, um trabalho chinês empregou métodos de proteômica para identificar e quantificar proteínas predominantes no soro de pacientes tuberculosos tratados e não tratados, bem como os que concluíram o tratamento com sucesso e controles saudáveis. Da triagem de proteínas, selecionou-se algumas para validação em ELISA. Estas foram escolhidas baseadas na correlação com a TB e alterações observadas nas análises proteômicas. Os analitos pesquisados foram: Albumina (ALB), Inibidor de dissociação Rho-GDP 2 (ARHGDIB), Componente 3 do Complemento (C3), Ficolina 2 (FCN2), e Lipoproteína A (LPA) (WANG et al., 20I8).

Segundo resultados do ELISA, pode-se conferir uma queda notável nos níveis de ARHGDIB, C3, FNC2 e aumento na ALB e LPA quando comparados pacientes curados com não tratados, tais achados validam os resultados encontrados pelas metodologias proteômicas. Todas as proteínas em análise apresentaram significância estatística $(p<0.05)$ nos pacientes considerados curados para TB quando comparados com os não tratados (WANG et al., 2018).

A ALB se apresenta em concentrações baixas em inflamações e, sendo assim, se mostrou consideravelmente reduzida em pacientes não tratados quando em comparação com controles $(p<0.00 \mathrm{I})$ (WANG et al., 20I8). Outros estudos já descreveram conexão entre hipoalbuminemia e risco de contrair TB (CEGIELSKI; ARAB; CORNONI-HUNTLEY, 20I2), da mesma forma aumentando o risco de morte pela infecção, porém não confirmando a ALB como uma variável independente para este desfecho (KIM et al., 20I2). Contudo, cabe observar outros trabalhos em áreas de pesquisa não relacionadas a TB ou mesmo quaisquer doenças respiratórias, que também relataram conexão entre hipoalbuminemia e mau prognóstico, inclusive em diferentes populações (BOHL et al., 20I6; MINATOGUCHI et al., 20I8; WADA et al., 20I7).

Sem papel fisiológico bem definido e geralmente associada a patologias cardiovasculares (SCHMIDT et al., 20I6), a LPA também foi considerada significante na análise $(\mathrm{p}=0.00 \mathrm{I})$ não tratados vs. controles. Do mesmo modo, discrepâncias em outras moléculas envolvidas no metabolismo de lipídios, como a Lipoproteína de alta densidade (HDL), Lipoproteína de baixa densidade ( $L D L)$, apolipoproteína $A$ (apoA) e a apolipoproteína $B$ (apoB) (WANG et al., 2018). Alterações nesses e outros analitos lipídicos se repetem em outras experiências de diferentes contextos, já explorados nesta revisão (ALBANNA et al., 20I3; XU et al., 20I4), entretanto, 
a LPA em específico não parece ser o biomarcador mais adequado para monitoramento de quimioterapias, sequer um marcador de cura, pois apresenta concentrações séricas muito singulares, não só entre indivíduos, mas igualmente entre populações (BANERJEE et al., 20I I; GAW et al., I994; SANDHOLZER et al., I99I).

ARHGDIB está envolvida em processos imunes (SAID et al., 20I2) e regulação da matriz extracelular (YI et al., 20 I4). A expressão desse biomarcador foi alta em não tratados quando frente a controles $(p=0.003)$ e diminuída nos considerados curados $(p<0.001)$, sem diferença considerável entre curados e controles. Os autores sugerem que a geração dos granulomas possa ser afetada pela regulação da matriz extracelular, com a destruição desta ocasionada pela ação da ARHGDIB, havendo aumento nos pacientes não tratados seguido da redução nos curados. No entanto essa hipótese é fundada em trabalhos que retratam o papel da ARHGDIB na perspectiva oncológica e reprodutiva (JUN CHO et al., 20 I4; LIU et al., 20 I4; YI et al., 20I4), sendo interessante futuros estudos para seu entendimento em modelos específicos de TB.

Níveis da ARHGDIB também se apresentaram significativamente reduzidos em pacientes com baciloscopia positiva em comparação aos que apresentavam baciloscopia negativa $(P<0,00 \mathrm{I})$. Uma discrepância que é sugerida pelos autores estar relacionada a mudanças patológicas proliferativas nesses indivíduos - mediadas pelo biomarcador em questão - que teriam sido infectados com menores cargas bacterianas.

Os níveis séricos do C3 e FCN em pacientes curados também foram baixos $(p=0.035, p=0.018$, respectivamente). Ambas seriam proteínas com atividade no sistema complemento, levando a crer que os níveis reduzidos possam ser devido a atenuação das ativações constantes do complemento, sendo aliviado pela conclusão da fase ativa da inflamação (WANG et al., 2018). Proteínas do complemento são estudadas na literatura da tuberculose (CAl et al., 20I4; LUBBERS et al., 20I8; SENBAGAVALLI et al., 20I I), a FCN2 em específico apresenta alguns estudos com determinados pontos conflitantes, especialmente em relação ao impacto de seus genótipos na infecção (CHALMERS et al., 20I5; LUO et al., 20I3; XU et al., 20I5).

Além disso a FCN2 se mostrou significativamente aumentada em pacientes positivos para baciloscopia em comparação com os negativos $(p=0.016)$, cogitando-se que pacientes negativos para o exame tenham maior probabilidade de infecções latentes, logo, com ativação limitada do complemento. Entretanto a discrepância deste raciocínio para com o C3 - que faz parte de uma cascata iniciada pela FCN2 - não é abordada na linha de raciocínio dos pesquisadores (WANG et al., 2018).

ALB e FCN tiveram altas substanciais observadas em pacientes com 2 meses de quimioterapia $(\mathrm{p}<$ $0.00 \mathrm{I}, \mathrm{p}=0.030$, respectivamente), o que pode sugerir valor preditivo destes biomarcadores para sucesso da terapia. No entanto, os pesquisadores não trabalharam com pacientes quais o tratamento tenha falhado, logo este ponto requer investigações mais cautelosas (WANG et al., 20I8).

Os autores, em conclusão, criaram um modelo para cura da TB que engloba os 5 analitos pesquisados, chegando a $87.10 \%$ de sensibilidade e $79.49 \%$ em especificidade, o que é uma performance considerável, ainda que longe do ideal. Todavia, os biomarcadores do estudo não são específicos para TB, pois se tratam de moléculas relacionadas a processos inflamatórios indefinidos ou, no caso da LPA, majoritariamente ao metabolismo de lipídios. $O$ trabalho tampouco incluiu em suas análises pacientes com outras doenças (respiratórias ou não), como mais um controle para as diferentes apresentações possíveis que estes analitos poderiam estar sujeitos em outros modelos (WANG et al., 20I8).

\section{Conclusão}

O diagnóstico e acompanhamento efetivos da Tuberculose ainda são desafios a serem vencidos dentro da medicina moderna. Os altos padrões requeridos para o biomarcador ideal são bastante difíceis de serem alcançados graças aos complexos mecanismos de autopreservação e transmissão criados pelo patógeno em todos os milhares de anos de coevolução com os hospedeiros humanos, aliados a heterogeneidade da resposta imune e os incontáveis fatores socioeconômicos e ambientais envolvidos na conservação da doença enquanto problema de saúde pública.

As pesquisas revisadas neste trabalho - ainda que em grande parte estudos pilotos investigando novos biomarcadores - apresentam populações muito restritas em seus ensaios, o que sem dúvida coloca em questionamento seus resultados. A pesquisa sorológica por antígenos e anticorpos obteve respostas discrepantes, muitas vezes inconstantes quando comparados os trabalhos. Isto, um provável fruto das diferentes cepas do Mycobacterium tuberculosis e o feedback imunológico irregular entre as populações e etnias. 
A homologia de antígenos micobacterianos com outras Mycobacteria e actinomicetos, bem como as mutações genéticas associadas a expressão de biomarcadores inflamatórios também foram obstáculos observados. Orienta-se que exista maior interação entre o diagnóstico sorológico e a biologia molecular nas pesquisas por biomarcadores, pois muitas discordâncias podem ser melhor averiguadas e até mesmo esclarecidas à luz das técnicas moleculares.

Biomarcadores bioquímicos se mostraram bastante significativos dentro do que foi observado. Maiores estudos incluindo populações com indivíduos afligidos por outras doenças respiratórias e outros grupos importantes para validação (como crianças e pacientes HIV+) naturalmente são recomendados.

Em suma, apesar dos resultados promissores em pequena escala, os testes sorológicos observados oferecem resultados inconsistentes. Sugerem-se maiores estudos em grandes populações, preferencialmente intercontinentais e com metodologias baratas e flexíveis como o ELISA aliadas a métodos moleculares confirmatórios na validação dos seus resultados. Preza-se que futuras metodologias efetivas, elegíveis para emprego em larga escala, sejam acessíveis a países pobres e subdesenvolvidos, portanto visando a população menos favorecida economicamente, que é, afinal de contas, a mais assolada pelo patógeno.

\section{Referências}

AABYE, M. G. et al. A simple method to quantitate IP-10 in dried blood and plasma spots. PLoS ONE, [s. I.], v. 7, n. 6, p. e39228, 2012.

AFZAL, M. et al. Fusion of selected regions of mycobacterial antigens for enhancing sensitivity in serodiagnosis of tuberculosis. Journal of Microbiological Methods, [s. I.], v. II I, p. I04-III, 2015.

ALBANNA, A. S. et al. Serum lipids as biomarkers for therapeutic monitoring of latent tuberculosis infection. European Respiratory Journal, [s. I.], v. 42, n. 2, p. 547-550, 2013.

ANDERSSON, J. et al. Impaired Expression of Perforin and Granulysin in CD8+ T Cells at the Site of Infection in Human Chronic Pulmonary Tuberculosis. Infection and Immunity, [s. I.], v. 75, n. I I, p. 52 I 0-5222, 2007.

ASHENAFI, S. et al. Progression of clinical tuberculosis is associated with a Th2 immune response signature in combination with elevated levels of SOCS3. Clinical Immunology, [s. I.], v. I5I, n. 2, p. 84-99, 2014.

ATKINSON, A. J. et al. Biomarkers and surrogate endpoints: Preferred definitions and conceptual framework. Clinical Pharmacology \& Therapeutics, [s. I.], v. 69, n. 3, p. 89-95, 2001.

AWONIYI, D. O. et al. Detection of a combination of serum IgG and IgA antibodies against selected mycobacterial targets provides promising diagnostic signatures for active TB. Oncotarget, [s. I.], v. 8, n. 23, p. 37525-37537, 2017.

BANERJEE, D. et al. Racial and Ethnic Variation in Lipoprotein (a) Levels among Asian Indian and Chinese Patients. Journal of Lipids, [s. I.], v. 20II, p. I-6, 201 I.

BAUMANN, R. et al. Serodiagnostic markers for the prediction of the outcome of intensive phase tuberculosis therapy. Tuberculosis, [s. I.], v. 93, n. 2, p. 239-245, 2013.

BAUMANN, R. et al. Serologic diagnosis of tuberculosis by combining lg classes against selected mycobacterial targets. Journal of Infection, [s. I.], v. 69, n. 6, p. 58I-589, 2014.

BHATTACHARYYA, T. et al. IgGI as a Potential Biomarker of Post-chemotherapeutic Relapse in Visceral Leishmaniasis, and Adaptation to a Rapid Diagnostic Test. PLoS Neglected Tropical Diseases, [s. I.], v. 8, n. I0, p. e3273, 2014.

BLACK, G. F. et al. Immunogenicity of novel DosR regulon-encoded candidate antigens of mycobacterium tuberculosis in three high-burden populations in Africa. Clinical and Vaccine Immunology, [s. I.], v. 16, n. 8, p. I203-12 I2, 2009.

BOHL, D. D. et al. Is Hypoalbuminemia Associated With Septic Failure and Acute Infection After Revision Total Joint Arthroplasty? A Study of 4517 Patients From the National Surgical Quality Improvement Program. The Journal of arthroplasty, [s. I.], v. 31, n. 5, p. 963-7, 2016.

BRASIL. Ministério da Saúde. Secretaria de Vigilância em Saúde. Departamento de Vigilância Epidemiológica. Manual Nacional de Vigilância Laboratorial da Tuberculose e outras Micobactérias. Brasília, DF, 2008. Disponível em: $<$ http://bvsms.saude.gov.br/bvs/publicacoes/manual_vigilancia_laboratorial_tuberculose.pdf $>$. Acesso em: 01 dez. 2018.

CAI, Y. et al. Increased Complement Clq Level Marks Active Disease in Human Tuberculosis. PLoS ONE, [s. I.], v. 9 , n. 3, p. e92340, 2014. 
CAO, S. H. et al. Screening of Serum Biomarkers for Distinguishing between Latent and Active Tuberculosis Using Proteome Microarray. Biomedical and environmental sciences : BES, [s. I.], v. 3I, n. 7, p. 5I5-526, 2018.

CEGIELSKI, J. P.; ARAB, L.; CORNONI-HUNTLEY, J. Nutritional Risk Factors for Tuberculosis Among Adults in the United States, 197I-1992. American Journal of Epidemiology, [s. I.], v. I76, n. 5, p. 409-422, 2012.

CHADHA, V. K. et al. Sensitivity and specificity of screening tools and smear microscopy in active tuberculosis case finding. Indian Journal of Tuberculosis, [s. I.], jun. 2018.

CHALMERS, J. D. et al. No Strong Relationship Between Components of the Lectin Pathway of Complement and Susceptibility to Pulmonary Tuberculosis. Inflammation, [s. I.], v. 38, n. 4, p. I73I-I737, 2015.

CHEN, C. et al. Identification of a novel serum biomarker for tuberculosis infection in Chinese HIV patients by iTRAQ-based quantitative proteomics. Frontiers in Microbiology, [s. I.], v. 9, n. FEB 26, p. 330-343, 20I8. a.

CHEN, T. et al. Profiling the human immune response to Mycobacterium tuberculosis by human cytokine array. Tuberculosis, [s. I.], v. 97, p. I08-II7, 2016.

CHEN, Y. et al. Potential role for Rv2026c- and Rv242 I c- specific antibody responses in diagnosing active tuberculosis. Clinica Chimica Acta, [s. I.], v. 487, p. 369-376, 2018. b.

CHUNG, W. Y. et al. The Usefulness of Serum CXCR3 Ligands for Evaluating the Early Treatment Response in Tuberculosis: A Longitudinal Cohort Study. Medicine (United States), [s. I.], v. 95, n. 17, p. e3575, 2016.

CLIFF, J. M. et al. Distinct phases of blood gene expression pattern through tuberculosis treatment reflect modulation of the humoral immune response. Journal of Infectious Diseases, [s. I.], v. 207, n. I, p. 18-29, 2013.

COSCOLLA, M.; GAGNEUX, S. Consequences of genomic diversity in mycobacterium tuberculosis. Semin Immunol., 26(6), 43I-44, 20I4. DOI: I0.1016/j.smim.20I4.09.0I2.

DANIEL, T. M. The history of tuberculosis. Respiratory Medicine, [s. I.], v. I00, n. I I, p. I862-I870, 2006.

DATTA, M. et al. Anti-vascular endothelial growth factor treatment normalizes tuberculosis granuloma vasculature and improves small molecule delivery. Proceedings of the National Academy of Sciences of the United States of America, [s. I.], v. II2, n. 6, p. I827-32, 2015.

DENKINGER, C. M. et al. Gamma Interferon Release Assay for Monitoring of Treatment Response for Active Tuberculosis: an Explosion in the Spaghetti Factory. Journal of Clinical Microbiology, [s. I.], v. 5I, n. 2, p. 607-6I0, 2013.

FAHEY, R. C. Novel thiols of prokaryotes. Annu Rev Microbiol, [s. I.], v. 55, n. I, p. 333-356, 200 I.

FENG, X. et al. Enhanced serodiagnostic utility of novel Mycobacterium tuberculosis polyproteins. Journal of Infection, [s. I.], v. 66, n. 4, p. 366-375, 2013.

FOGEL, N. Tuberculosis: A disease without boundaries. Tuberculosis (Edinb), v. 95(5), 527-3I, 20I5. DOI: I0.10I6/j. tube.2015.05.017. Disponível em: <http://www.ncbi.nlm.nih.gov/pubmed/26।98II3>. Acesso em: 5 dez. 2018.

FUJITA, Y. et al. Diverse humoral immune responses and changes in lgG antibody levels against mycobacterial lipid antigens in active tuberculosis. Microbiology, [s. I.], v. I5I, n. 6, p. 2065-2074, 2005.

GAW, A. et al. Comparative analysis of the apo(a) gene, apo(a) glycoprotein, and plasma concentrations of Lp(a) in three ethnic groups. Evidence for no common \&quot;null\&quot; allele at the apo(a) locus. Journal of Clinical Investigation, [s. I.], v. 93, n. 6, p. 2526-2534, 1994.

GOUMANS, M. J.; LIU, Z.; TEN DIJKE, P. TGF- $\square$ signaling in vascular biology and dysfunction. Cell Research, v. I9, p. II6-127, 2009.

GUGGINO, G. et al. Granzyme A as a potential biomarker of Mycobacterium tuberculosis infection and disease. Immunology Letters, [s. I.], v. I66, n. 2, p. 87-91, 2015.

GUPTA, R. K. et al. Impact of human immunodeficiency virus and CD4 count on tuberculosis diagnosis: Analysis of city-wide data from Cape Town, South Africa. International Journal of Tuberculosis and Lung Disease, [s. I.], v. 17, n. 8, p. 1014-1022, 2013.

GUPTA, S. et al. IgG subclass antibody response to mycobacterial serine protease at different stages of pulmonary tuberculosis. Medical science monitor: international medical journal of experimental and clinical research, [s. I.], v. II, n. I2, p. CR585-8, 2005. 
GUTHRIE, R.; SUSI, A. A simple phenylalanine method for detecting phenylketonuria in large populations of newborn infants. Pediatrics, [s. I.], v. 32, n. 32, p. 338-343, 1963.

HARRIS, J. et al. T Helper 2 Cytokines Inhibit Autophagic Control of Intracellular Mycobacterium tuberculosis. Immunity, [s. I.], v. 27, n. 3, p. 505-5I7, 2007.

HONG, J. Y. et al. Efficacy of IP-I0 as a biomarker for monitoring tuberculosis treatment. Journal of Infection, [s. I.], v. 68, n. 3, p. 252-258, 2014.

HOSSEINI, S. et al. Enzyme-linked immunosorbent assay (ELISA) : from A to Z. [s.I.], Springer. 2018.

HSIANG, E. et al. Higher cost of implementing Xpert $<$ SUP $>\AA</ S U P>M T B / R I F$ in Ugandan peripheral settings: implications for cost-effectiveness. The International Journal of Tuberculosis and Lung Disease, [s. I.], v. 20, n. 9, p. $1212-1218,2016$.

IMAZ, M. S.; ZERBINI, E. Antibody response to culture filtrate antigens of Mycobacterium tuberculosis during and after treatment of tuberculosis patients. International Journal of Tuberculosis and Lung Disease, [s. I.], v. 4, n. 6, p. 562-569, 2000.

ISEMAN, M. D. Tuberculosis therapy: past, present and future. European Respiratory Journal, [s. I.], v. 20, n. Supplement 36, p. 87S-94s, 2002.

JAYAKUMAR, A. et al. Serum biomarkers of treatment response within a randomized clinical trial for pulmonary tuberculosis. Tuberculosis, [s. I.], v. 95, n. 4, p. 4I5-420, 2015.

JUN CHO, H. et al. VEGF-C mediates RhoGDI2-induced gastric cancer cell metastasis and cisplatin resistance. International Journal of Cancer, [s. I.], v. I35, n. 7, p. I553-I563, 2014.

KASSA, D. et al. Analysis of immune responses against a wide range of Mycobacterium tuberculosis antigens in patients with active pulmonary tuberculosis. Clinical and Vaccine Immunology, [s. I.], v. 19, n. I2, p. 1907-1915, 2012.

KIM, C. W. et al. Risk Factors Related with Mortality in Patient with Pulmonary Tuberculosis. Tuberculosis and Respiratory Diseases, [s. I.], v. 73, n. I, p. 38, 2012.

KUNNATH-VELAYUDHAN, S. et al. Dynamic antibody responses to the Mycobacterium tuberculosis proteome. Proceedings of the National Academy of Sciences of the United States of America, [s. I.], v. I07, n. 33, p. I4703-8, 2010.

LEE, K. et al. CXCR3 ligands as clinical markers for pulmonary tuberculosis. The International Journal of Tuberculosis and Lung Disease, [s. I.], v. 19, n. 2, p. 191-199, 2015.

LEGESSE, M. et al. IgA Response to ESAT-6/CFP-I0 and Rv203I Antigens Varies in Patients With Culture-Confirmed Pulmonary Tuberculosis, Healthy Mycobacterium tuberculosis-Infected and Non-Infected Individuals in a Tuberculosis Endemic Setting, Ethiopia. Scandinavian Journal of Immunology, [s. I.], v. 78, n. 3, p. 266-274, 2013.

LIU, Q. Y. et al. Inflammation responses in patients with pulmonary tuberculosis in an intensive care unit. Experimental and Therapeutic Medicine, [s. I.], v. I5, n. 3, p. 2719-2726, 2018.

LIU, S. et al. RhoGDI2 Is Expressed in Human Trophoblasts and Involved in Their Migration by Inhibiting the Activation of RACI I. Biology of Reproduction, [s. I.], v. 90, n. 4, 2014.

LÓPEZ-RAMOS, J. E. et al. Improvement in the Diagnosis of Tuberculosis Combining Mycobacterium Tuberculosis Immunodominant Peptides and Serum Host Biomarkers. Archives of Medical Research, [s. I.], v. 49, n. 3, p. I47-I53. el, 2018.

LUBBERS, R. et al. Complement component $\mathrm{Clq}$ as serum biomarker to detect active tuberculosis. Frontiers in Immunology, [s. I.], v. 9, p. 2427, 2018.

LUO, F. et al. Ficolin-2 Defends against Virulent Mycobacteria Tuberculosis Infection In Vivo, and Its Insufficiency Is Associated with Infection in Humans. PLoS ONE, [s. I.], v. 8, n. 9, p. e73859, 2013.

LUO, L. et al. Antigens Rv03 IOc and RvI255c are promising novel biomarkers for the diagnosis of Mycobacterium tuberculosis infection. Emerging Microbes and Infections, [s. I.], v. 6, n. 7, p. e64-e7I, 2017.

LYASHCHENKO, K. et al. Heterogeneous antibody responses in tuberculosis. Infection and Immunity, [s. I.], v. 66, n. 8, p. 3936-3940, 1998.

MATTOS, A. M. M. et al. Increased IgGI, IFN- $\gamma$, TNF- $\alpha$ and IL-6 responses to Mycobacterium tuberculosis antigens in patients with Tuberculosis are lower after chemotherapy. International Immunology, [s. I.], v. 22, n. 9, p. 775-782, 20 I 0. 
MATTOS, A. M. M. et al. Detection of IgGI antibodies against Mycobacterium tuberculosis DosR and Rpf antigens in tuberculosis patients before and after chemotherapy. Tuberculosis, [s. I.], v. 96, p. 65-70, 2016.

MAY, Y. L. et al. Cross-reactive immunity to Mycobacterium tuberculosis DosR regulon-encoded antigens in individuals infected with environmental, nontuberculous mycobacteria. Infection and Immunity, [s. I.], v. 77, n. II, p. 507I-5079, 2009.

MENZIES-GOW, A. et al. Eotaxin (CCLI I) and Eotaxin-2 (CCL24) Induce Recruitment of Eosinophils, Basophils, Neutrophils, and Macrophages As Well As Features of Early- and Late-Phase Allergic Reactions Following Cutaneous Injection in Human Atopic and Nonatopic Volunteers. The Journal of Immunology, [s. I.], v. I69, n. 5, p. 27I 2-27I8, 2002.

MINATOGUCHI, S. et al. Low serum albumin as a risk factor for infection-related in-hospital death among hemodialysis patients hospitalized on suspicion of infectious disease : a Japanese multicenter retrospective cohort study. Renal Replacement Therapy, [s. I.], v. 4, n. I, p. I-7, 2018.

MURRAY, J. F.; SCHRAUFNAGEL, D. E.; HOPEWELL, P. C. Treatment of tuberculosis: A historical perspective. Annals of the American Thoracic Society, [s. I.], v. I2, n. 12, p. 1749-1759, 2015.

NIKI, M. et al. Evaluation of Humoral Immunity to Mycobacterium tuberculosis -Specific Antigens for Correlation with Clinical Status and Effective Vaccine Development. Journal of Immunology Research, [s. I.], v. 20I5, p. I-I3, 20 I5.

OEHLERS, S. H. et al. Interception of host angiogenic signalling limits mycobacterial growth. Nature, [s. I.], v. 5 I 7, n. 7536, p. 6I2-615, 2015.

OMS - Organização Mundial da Saúde. Global tuberculosis report 2018. Geneva: World Health Organization, 2018. Disponível em: <http://www.who.int/tb/publications/global_report/en/>. Acesso em: 0I dez. 2018.

OMS - Organização Mundial da Saúde. High-priority target product profi les for new tuberculosis diagnostics: report of a consensus meeting. Geneva: World Health Organization, 2014. Disponível em: <https://www.who.int/ tb/publications/tpp_report/en/>. Acesso em: I4 mai. 2018.

OMS - Organização Mundial da Saúde. Tuberculosis: A global emergency, WHO report on the TB epidemic. Geneva: World Health Organization, 1994. Disponível em: <http://apps.who.int/iris/handle/I0665/58749>. Acesso em: I4 mai. 2018.

PARK, J. Y.; KRICKA, L. J. Interferences in Immunoassay. In: The Immunoassay Handbook, [s.I: s.n.], 2008. p. $403-416$.

PARSONS, L. M. et al. Laboratory diagnosis of tuberculosis in resource-poor Countries: Challenges and opportunities, American Society for Microbiology (ASM), [s. I.], v. 24, n. 2, p. 3I4-350, 20 I I.

PITABUT, N. et al. Decreased plasma granulysin and increased interferon-gamma concentrations in patients with newly diagnosed and relapsed tuberculosis. Microbiology and Immunology, [s. I.], v. 55, n. 8, p. 565-573, 201 I.

PITABUT, N. et al. Potential function of granulysin, other related effector molecules and lymphocyte subsets in patients with TB and HIV/TB coinfection. International Journal of Medical Sciences, [s. I.], v. I0, n. 8, p. I003-I0I4, 2013.

POLENA, H. et al. Mycobacterium tuberculosis exploits the formation of new blood vessels for its dissemination. Scientific Reports, [s. I.], v. 6, n. I, p. 33162, 2016.

PURI, L. et al. Xpert MTB/RIF for tuberculosis testing: access and price in highly privatised health markets. The Lancet Global Health, [s.l.], v. 4, n. 2, 94-95, 2016.

RIVA, M. A. From milk to rifampicin and back again: History of failures and successes in the treatment for tuberculosis, Journal of Antibiotics, [s.l.], v. 67, n. 9, p. 66I-665, 2014.

REN, N. et al. Identification of new diagnostic biomarkers for Mycobacterium tuberculosis and the potential application in the serodiagnosis of human tuberculosis. Microbial Biotechnology, [s. I.], v. I I, n. 5, p. 893-904, 2018.

SAHIRATMADJA, E. et al. Plasma granulysin levels and cellular interferon- $\square$ production correlate with curative host responses in tuberculosis, while plasma interferon- $\square$ levels correlate with tuberculosis disease activity in adults. Tuberculosis, [s. I.], v. 87, n. 4, p. 312-321, 2007.

SAID, N. et al. RhoGDI2 suppresses lung metastasis in mice by reducing tumor versican expression and macrophage infiltration. Journal of Clinical Investigation, [s. I.], v. I22, n. 4, p. I503-I5I8, 2012.

SALLUSTO, F.; MACKAY, C. R.; LANZAVECCHIA, A. Selective expression of the eotaxin receptor CCR3 by human T helper 2 cells. Science, [s. I.], v. 277, n. 5334, p. 2005-2007, 1997. 
SANDHOLZER, C. et al. Effects of the apolipoprotein(a) size polymorphism on the lipoprotein(a) concentration in 7 ethnic groups. Human Genetics, [s. I.], v. 86, n. 6, I99I.

SCHMIDT, K. et al. Structure, function, and genetics of lipoprotein (a). Journal of Lipid Research, [s. I.], v. 57, n. 8, p. 1339-1359, 2016.

SECRETARIA DE VIGILÂNCIA EM SAÚDE. Implantação do Plano Nacional pelo Fim da Tuberculose como Problema de Saúde Pública no Brasil: primeiros passos rumo ao alcance das metas. Bol. Epidemiol., v. 49, n. II, p. I-I8, 2018. Disponível em: <http://portalarquivos2.saude.gov.br/images/pdf/20l8/marco/26/20l8-009.pdf>Acesso em: 01 dez. 2018.

SENBAGAVALLI, P. et al. Major histocompatibility complex class III (C2, C4, factor B) and C3 gene variants in patients with pulmonary tuberculosis. Human Immunology, [s. I.], v. 72, n. 2, p. I73-I78, 20 II.

SERRA-VIDAL, M. et al. Immunogenicity of 60 novel latency-related antigens of Mycobacterium tuberculosis. Frontiers in Microbiology, [s. I.], v. 5, n. SEP, p. 517, 2014.

SHANG, Z. B. et al. Serum macrophage migration inhibitory factor as a biomarker of active pulmonary tuberculosis. Annals of Laboratory Medicine, [s. I.], v. 38, n. I, p. 9-16, 2018.

SHARMA, S. K. et al. Comparison of TST and IGRA in diagnosis of latent tuberculosis infection in a high TB-burden setting. PLoS ONE, [s. I.], v. I2, n. I, p. e0169539, 2017.

SHIMONO, N. et al. Hypervirulent mutant of Mycobacterium tuberculosis resulting from disruption of the mcel operon. Proceedings of the National Academy of Sciences, [s. I.], v. I00, n. 26, p. I59I8-I5923, 2003.

SIEV, M. et al. Antibodies against mycobacterial proteins as biomarkers for HIV-associated smear-negative tuberculosis. Clinical and Vaccine Immunology, [s. I.], v. 2I, n. 6, p. 79I-798, 20 I4.

SIRECI, G. et al. Anti-I6-Kilodalton Mycobacterial Protein Immunoglobulin M Levels in Healthy but Purified Protein Derivative-Reactive Children Decrease after Chemoprophylaxis. Clinical and Vaccine Immunology, [s. I.], v. I4, n. 9, p. $1231-1234,2007$

SRIVASTAVA, V. et al. Macrophage-specific Mycobacterium tuberculosis genes: Identification by green flourescent protein and kanamycin resistance selection. Microbiology, [s. I.], v. I53, n. 3, p. 659-666, 2007.

STEINGART, K. R. et al. Commercial Serological tests for the diagnosis of active pulmonary and extrapulmonary tuberculosis: An updated systematic review and Meta-Analysis, PLoS Medicine, [s. I.], v. 8, n. 8, el 00 I062, 201 I.

SUTHERLAND, J. S. et al. Analysis of Host Responses to Mycobacterium tuberculosis Antigens in a Multi-Site Study of Subjects with Different TB and HIV Infection States in Sub-Saharan Africa. PLoS ONE, [s. I.], v. 8, n. 9, p. e74080, 20 I 3.

TAKENAMI, I. et al. Immunoglobulin G response to mammalian cell entry IA (Mce IA) protein as biomarker of active tuberculosis. Tuberculosis, [s. I.], v. 100, p. 82-88, 2016.

THUONG, P. H. et al. Circulating granulysin levels in healthcare workers and latent tuberculosis infection estimated using interferon-gamma release assays. BMC Infectious Diseases, [s. I.], v. I6, n. I, p. 580-589, 2016.

TONBY, K. et al. IP-I0 measured by Dry Plasma Spots as biomarker for therapy responses in Mycobacterium Tuberculosis infection. Scientific Reports, [s. I.], v. 5, n. I, p. 9223, 2015.

UCHIDA, Y. et al. Accelerated immunopathological response of mice infected with Mycobacterium tuberculosis disrupted in the mcel operon negative transcriptional regulator. Cellular Microbiology, [s. I.], v. 9, n. 5, p. I275-I $283,2007$.

WADA, H. et al. Independent and Combined Effects of Serum Albumin and C-Reactive Protein on Long-Term Outcomes of Patients Undergoing Percutaneous Coronary Intervention. Circulation Journal, [s. I.], v. 8I, n. 9, p. I293-I300, 2017.

WANG, C. et al. Screening and identification of four serum miRNAs as novel potential biomarkers for cured pulmonary tuberculosis. Tuberculosis, [s. I.], v. I08, n. I, p. 26-34, 2018.

WANG, Q. et al. MPT64 protein from Mycobacterium tuberculosis inhibits apoptosis of macrophages through NF-kB-miRNA2I-Bcl-2 pathway. PLoS ONE, [s. I.], v. 9, n. 7, p. el00949, 2014.

XU, D.-D. et al. Association of the FCN2 Gene Single Nucleotide Polymorphisms with Susceptibility to Pulmonary Tuberculosis. PLOS ONE, [s. I.], v. I0, n. 9, p. e0I38356, 2015.

$X U, D$. D. et al. Discovery and identification of serum potential biomarkers for pulmonary tuberculosis using iTRAQ-coupled two-dimensional LC-MS/MS. Proteomics, [s. I.], v. I4, n. 2-3, p. 322-33I, 2014. 
YI, B. et al. Depletion of RhoGDI2 expression inhibits the ability of invasion and migration in pancreatic carcinoma. International Journal of Molecular Medicine, [s. I.], v. 34, n. I, p. 205-212, 2014.

YUAN, Y. et al. The 16-kDa alpha-crystallin (Acr) protein of Mycobacterium tuberculosis is required for growth in macrophages. Proceedings of the National Academy of Sciences of the United States of America, [s. I.], v. 95, n. 16, p. 9578-83, 1998.

YUAN, Y.; CRANE, D. D.; BARRY, C. E. Stationary phase-associated protein expression in Mycobacterium tuberculosis: Function of the mycobacterial $\alpha$-crystallin homolog. Journal of Bacteriology, [s. I.], v. I 78, n. I5, p. 4484-4492, 1996.

ZEITOUN, H. et al. Mycothiol acetyltransferase (Rv08I9) of Mycobacterium tuberculosis is a potential biomarker for direct diagnosis of tuberculosis using patient serum specimens. Letters in Applied Microbiology, [s. I.], v. 65, n. 6, p. 504-5II, 2017.

ZHANG, C. et al. Mycobacterium tuberculosis Secreted Proteins As Potential Biomarkers for the Diagnosis of Active Tuberculosis and Latent Tuberculosis Infection. Journal of Clinical Laboratory Analysis, [s. I.], v. 29, n. 5, p. 375-382, 2014.

ZHAO, Y. et al. IP-IO and RANTES as biomarkers for pulmonary tuberculosis diagnosis and monitoring. Tuberculosis, [s. I.], v. III, p. 45-53, 2018. 